\title{
Determination of Iron and Zinc in Garbanzo by Microwave Digestion-High Resolution Continuum Source Flame Atomic Absorption Spectrometry
}

\author{
Quan-de Liu', Shang-long Chen ${ }^{b}$, Yong Lic ${ }^{\mathrm{c}}$, Jing Gao ${ }^{\mathrm{d}}$, Yun-Xu Zhu ${ }^{\mathrm{e}}$ \\ Jiangsu Key Laboratory of Food Resource Development and Quality Safe, Xuzhou Institute of \\ Technology, Xuzhou China 221111 \\ aqd@xzit.edu.cn, bslchen1982@163.com, c1507674085@qq.com, d1318134737@qq.com, \\ 6609116239@qq.com
}

\begin{abstract}
Keywords: Iron; zinc; garbanzo; microwave digestion; HR-CS FAAS
Abstract. A new application of high resolution continuum source flame atomic absorption spectrometry has been developed for the determination of $\mathrm{Fe}$ and $\mathrm{Zn}$ in garbanzo. The selected fuel flows of $\mathrm{Fe}$ and $\mathrm{Zn}$ were $80 \mathrm{~L} / \mathrm{h}$ and $90 \mathrm{~L} / \mathrm{h}$ respectively, and the appropriate burner heights of $\mathrm{Fe}$ and $\mathrm{Zn}$ were $5 \mathrm{~mm}$ and $6 \mathrm{~mm}$ respectively by single factor experiments. Under the optimum working conditions, the proposed methods are fast, inexpensive and show good performances: the relative standard deviations were less than $2.6 \%$, good correlation coefficients and the recoveries of $\mathrm{Fe}$ and $\mathrm{Zn}$ were $96.7 \% \pm 2.5 \%$ and $94.3 \% \pm 3.1 \%$, respectively. The results showed that the contents of $\mathrm{Fe}$ and $\mathrm{Zn}$ in garbanzo were $68.6 \pm 1.5 \mathrm{mg} / \mathrm{kg}$ and $18.1 \pm 0.6 \mathrm{mg} / \mathrm{kg}$, respectively. Therefore, the proposed method was accurate and stable with a high practical value. It provided scientific basis for determination of metal elements in food.
\end{abstract}

\section{Introduction}

Several sample preparation techniques are used for the determination of metal elements in food, such as inductively wet digestion, dry digestion, incomplete digestion and microwave digestion. Wet digestion and dry digestion are two traditional ways, but both of them have obvious disadvantages, for instance, some dense mass of strong acids are used in wet digestion, while dry digestion is a time-consuming process[1,2]. The objective of incomplete digestion is uniform and transparent digestive solutions, which do not need of complete destruction and colorless liquors. As a consequence of that, the sample-process time just need less than $20 \mathrm{~min}[3]$. Nevertheless, incomplete digestion also requires a good deal of strong acids and the microemulsification stability after that is an important parameter for accurate analysis. Closed-vessel microwave-assisted digestion need only $5 \mathrm{~mL}$ of $\mathrm{HNO}_{3}$ and $4 \mathrm{~mL} \mathrm{H}_{2} \mathrm{O}_{2}$ in this study, and its main advantages are the high relative speed, good reproducibility, low blank, low possibility of contamination and the minimum loss of volatile elements [4].

The objective of this study was to develop a simple and robust method for the fast sequential multi-element determination of $\mathrm{Fe}[5]$ and $\mathrm{Zn}$ [2] in garbanzo by high resolution continuum source flame atomic absorption spectrometry (HR-CS FAAS)[6-9] using new features.

\section{Experimental}

Instrumentation

An Analytik Jena ContrAA 700 High Resolution Continuum Source Atomic Absorption Spectrometer (Analytik Jena, Berlin,Germany) had been used for all measurements in this work. This spectrometer consists of a high-intensity xenon short-arc lamp, a high-resolution double echelle monochromator (DEMON) and a chargecoupled device (CCD) array detector[10]. All absorption lines in the range from $185 \mathrm{~nm}$ to $900 \mathrm{~nm}$ are provided by the high-intensity xenon short-arc lamp as the radiation source. The highest resolution of about $2 \mathrm{pm}$ is carried out by DEMON, including a pre-dispersing prism monochromator and a high-resolution echelle grating monochromator. 200 pixels of the linear CCD array detector are used for monitoring all spectral informations on both sides of center wavelength. The flame type was $\mathrm{C}_{2} \mathrm{H}_{2}$-air and the burner type 
was $100 \mathrm{~mm}$ in the process of determination. The fixed air flow was $470 \mathrm{~L} / \mathrm{h}$ for determination. The optimized determination conditions were shown in Table 1.

Table 1 Determination conditions of HR-CS FAAS

\begin{tabular}{ccccc}
\hline Element & Wavelength $(\mathrm{nm})$ & Spectr.range & Fuel flow $(\mathrm{L} / \mathrm{h})$ & Burner height $(\mathrm{mm})$ \\
\hline $\mathrm{Fe}$ & 248.327 & 200 & 80 & 5 \\
$\mathrm{Zn}$ & 213.857 & 200 & 90 & 6 \\
\hline
\end{tabular}

Reagents and standards

The reagents were of guaranteed reagent. Ultrapure water with a resistivity of $18.2 \mathrm{M} \Omega \cdot \mathrm{cm}$ was obtained from a Milli-Q system (Millipore, Billerica, USA). Calibration solutions were prepared in the ultrapure water with $0.5 \%(\mathrm{v} / \mathrm{v}) \mathrm{HNO}_{3}$ and $0.1 \%(\mathrm{~m} / \mathrm{m}) \mathrm{KCl}$ by serial dilution of the stock solutions with 100 mg/L Fe and Zn (National Chemical Reagent Company, Beijing, China). All glasswares were previously soaked overnight in dilute $\mathrm{HNO}_{3}(5 \% \mathrm{v} / \mathrm{v})$ for cleaning and were rinsed with abundant ultrapure water prior to avoid contamination.

Microwave digestion

The garbanzos were purchased from the supermarket (Xuzhou, China) during 2015 and analyzed of their Fe and $\mathrm{Zn}$ contents. They were crushed to powder. Approximately a $0.5 \mathrm{~g}$ of the crushed sample was preprocessed with $5 \mathrm{~mL}$ of $\mathrm{HNO}_{3}$ and $2 \mathrm{~mL} \mathrm{H}_{2} \mathrm{O}_{2}$ in the PTFE jar, which was the process of heating to $120{ }^{\circ} \mathrm{C}$ for $30 \mathrm{~min}$ in an air-ventilated oven. The compound (sample and acids) was digested in the intelligent microwave digestion system (Xin-tuo, Shanghai,China) after adding again $2 \mathrm{~mL} \mathrm{H}_{2} \mathrm{O}_{2}$. A five stage program (Table 2) with a maximum pressure of 2.0 Mpa was chosen for achieving complete digestion of the crushed sample within the shorter time. The digestive liquor was diluted to $25 \mathrm{~mL}$ with the ultrapure water with $0.5 \%$ (v/v) $\mathrm{HNO}_{3}$ and $0.1 \%$ $(\mathrm{m} / \mathrm{m}) \mathrm{KCl}$ when its volume was less than $3.0 \mathrm{~mL}$. Soon after that, it was hand shaken resulting in a visually homogeneous system. A blank digest was carried out in the same way. Three independent aboved treatments of the sample were performed for obtaining the average of repetitive determinations of $\mathrm{Fe}$ and $\mathrm{Zn}$.

Table 2 Microw ave digestion program

\begin{tabular}{cccc}
\hline Stages & Pressure (Mpa) & Hold (min.) & Power $(\mathrm{W})$ \\
\hline 1 & 0.2 & 60 & 500 \\
2 & 0.5 & 60 & 1000 \\
3 & 1.0 & 120 & 1000 \\
4 & 1.5 & 120 & 1000 \\
5 & 2.0 & 60 & 1000 \\
\hline
\end{tabular}

\section{Results and discussion}

Effect of fuel flow

An applicable fuel flow was extraordinary important to determination of Fe and Zn by HR-CS FAAS. Fig.1. showed the influence of the fuel flow on the absorbance in which the other experimental variables remained constant. The results showed that the absorbance of Fe increased as the fuel flow increased from 70 to $90 \mathrm{~L} / \mathrm{h}$ and then decreased, and that of $\mathrm{Zn}$ increased as the fuel flow increased from 70 to $80 \mathrm{~L} / \mathrm{h}$ and then decreased. To fulfill the "highest sensitivity", the fuel flows of Fe and $\mathrm{Zn}$ were $80 \mathrm{~L} / \mathrm{h}$ and $90 \mathrm{~L} / \mathrm{h}$ for the rest of this work, respectively.

Effect of burner height

An appropriate burner height was important to determination of Fe and Zn by HR-CS FAAS as well. The variation in absorbance within the burner height range of 4-8 $\mathrm{mm}$ was examined in which the other experimental variables remained constant. Fig.2. highlighted the differences observed in different burner heights. The burner heights of Fe and $\mathrm{Zn}$ were $5 \mathrm{~mm}$ and $6 \mathrm{~mm}$ for the rest of this work in order to achieve the optimal analytical signal, respectively. 


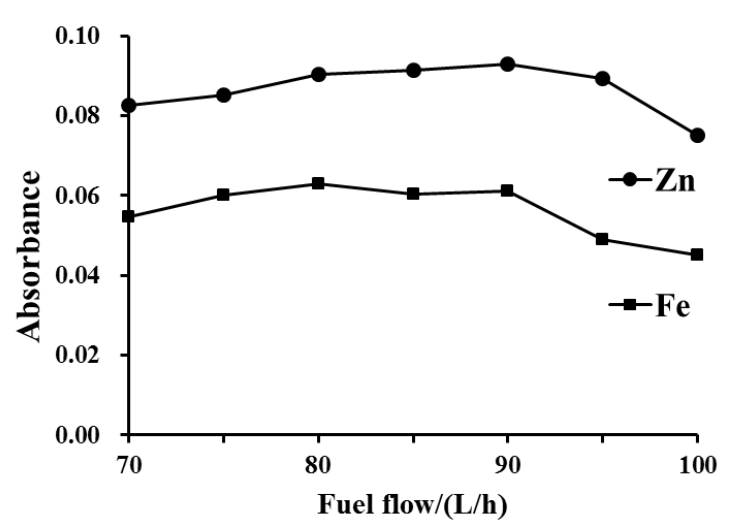

Fig.1. Effect of the fuel flow on absorbance.

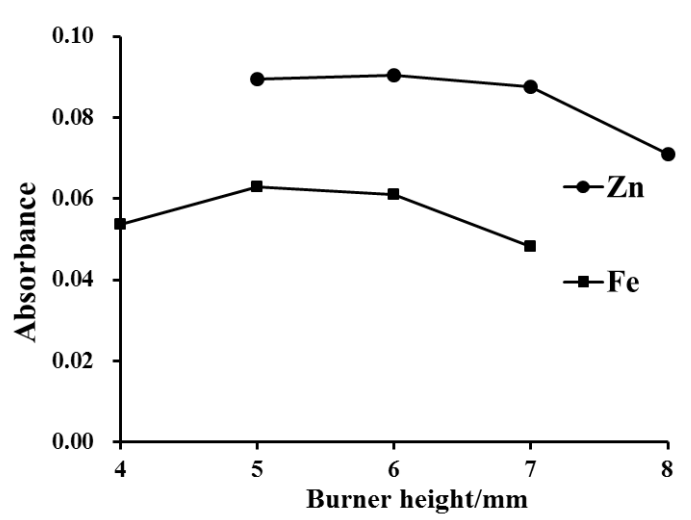

Fig.2. Effect of the burner height on absorbance.

\section{Analytical performance}

The analytical characteristic data of HR-CS FAAS were shown in Table 3. The calibration curves used to determine of $\mathrm{Fe}$ and $\mathrm{Zn}$ with HR-CS FAAS were built-up by measuring the absorbance of the calibration solutions in the optimum determination conditions, as shown in Fig.3.. The correlation coefficients better than 0.998 and the relative standard deviations less than $2.6 \%$ were obtained for $\mathrm{Fe}$ and $\mathrm{Zn}$. As can be seen, the proposed method represented one of more sensitive methodologies for determination of $\mathrm{Fe}$ and $\mathrm{Zn}$.

Table 3 Analytical characteristic data of HR-CS FAAS

\begin{tabular}{cccccc}
\hline Element & $\begin{array}{c}\text { Calibration function } \\
(C \text { in } \mathrm{mg} / \mathrm{L})\end{array}$ & $\begin{array}{c}\text { Correlation } \\
\text { coefficient } \\
\left(R^{2}\right)\end{array}$ & $\begin{array}{c}\text { Characteristic } \\
\text { concentration } \\
(\mathrm{mg} / \mathrm{L})\end{array}$ & $\begin{array}{c}\text { Concentration } \\
\text { range }(\mathrm{mg} / \mathrm{L})\end{array}$ & $\begin{array}{c}\text { Precision } \\
(\mathrm{RSD}, n=6)\end{array}$ \\
\hline $\mathrm{Fe}$ & $\mathrm{A}=\left(\begin{array}{c}-0.0013854+0.0256013 \times \mathrm{c}) \\
/(1+0.0194315 \times \mathrm{c})\end{array}\right.$ & 0.9996 & 0.17 & $0 \sim 5$ & $1.9 \%$ \\
$\mathrm{Zn}$ & $\mathrm{A}=\left(\begin{array}{c}-0.0018482+0.1311885 \times \mathrm{c}) \\
/(1+0.1288429 \times \mathrm{c})\end{array}\right.$ & 0.9989 & 0.033 & $0 \sim 4$ & $2.6 \%$ \\
\hline
\end{tabular}
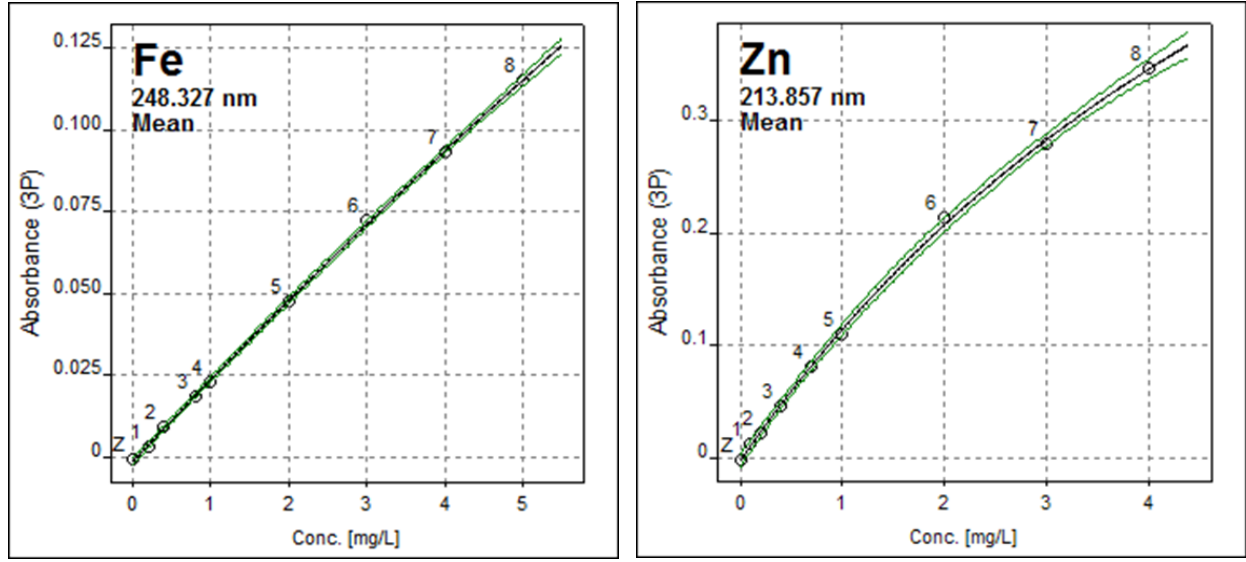

Fig.3. Calibration curve.

The proposed means, using microwave digestion-HR-CS FAAS, had been applied to determination of $\mathrm{Fe}$ and $\mathrm{Zn}$ in garbanzo. The results, obtained as the average of three replicates of each sample, shown that the contents of $\mathrm{Fe}$ and $\mathrm{Zn}$ in garbanzo were $68.6 \pm 1.5 \mathrm{mg} / \mathrm{kg}$ and $18.1 \pm$ $0.6 \mathrm{mg} / \mathrm{kg}$, respectively.

The proposed means was verified through spike recovery tests, by adding $50 \mathrm{mg} / \mathrm{kg}$ of Fe and $20 \mathrm{mg} / \mathrm{kg}$ of $\mathrm{Zn}$ to the crushed garbanzo. The results showed that the recoveries of Fe and $\mathrm{Zn}$ were $96.7 \% \pm 2.5 \%$ and $94.3 \% \pm 3.1 \%$, respectively[11]. The accuracy should be good and enough for a great many applications in other food. Therefore, the proposed method represented one of exacter and more sensitive methodologies for determination of Fe and $\mathrm{Zn}$ 


\section{Conclusions}

The developed means provided a exact and sensitive procedure for the determination of $\mathrm{Fe}$ and $\mathrm{Zn}$ in the garbanzo by HR-CS FAAS after microwave digestion. The selected fuel flows of $\mathrm{Fe}$ and $\mathrm{Zn}$ were $80 \mathrm{~L} / \mathrm{h}$ and $90 \mathrm{~L} / \mathrm{h}$ respectively, and the appropriate burner heights of Fe and $\mathrm{Zn}$ were $5 \mathrm{~mm}$ and $6 \mathrm{~mm}$ respectively by single factor experiments. Under the optimum working conditions, the contents of $\mathrm{Fe}$ and $\mathrm{Zn}$ in garbanzo were $68.6 \pm 1.5 \mathrm{mg} / \mathrm{kg}$ and $18.1 \pm 0.6 \mathrm{mg} / \mathrm{kg}$, respectively. The relative standard deviations were less than $2.6 \%$ and the recoveries of $\mathrm{Fe}$ and $\mathrm{Zn}$ were $96.7 \% \pm 2.5 \%$ and $94.3 \% \pm 3.1 \%$, respectively. Also, good correlation coefficients and precisions, and high recoveries showed that the proposed method is accuracy, reliability and stability.

\section{Acknowledgements}

This work was financially supported by the Open Project Program of Jiangsu Key Laboratory of Food Resource Development and Quality Safety, Xuzhou Institute of Technology (No. SPKF201317) and Spark Plan of China (No. 2013GA690417).

\section{References}

[1] Afridi H I, Kazi T G, Arain M B, et al. Determination of cadmium and lead in biological samples by three ultrasonic-based samples treatment procedures followed by electrothermal atomic absorption spectrometry[J]. Journal of AOAC International, 2007, 90(2): 470-478.

[2] Gao S Y. The Determination of Element Content in Burdock by Flame Atomic Absorption Spectrophotometry[J]. Journal of Xuzhou Institute of Technology, 2007, 6(22): 32-35.

[3] LIU L, YU M. Determination of calcium and magnesium in gelatin by noncomplete digestion-flame atomic absortion spectrometry [J]. Metallurgical Analysis, 2004, 5: 015.

[4] REN Ting, ZHAO Li-jiao, ZHONG Ru-gang. Determination of Aluminum in Wheat Flour Food by Microwave Digestion-High Resolution Continuous Source Graphite Furnace Atomic Absorption Spectrometry[J]. Spectroscopy and Spectral Analysis, 2011, 31(12):3388-3391.

[5] Miao J Z, Lv Z Q. The Study on the Bioenrichment of Iron in G.Lucidum by Deep-submerged Fermentation[J]. Journal of Xuzhou Institute of Technology, 2007, 6(22): 36-39.

[6] ALINE R B, EMILENE M B, CÉLINE L, et al. Method development for the determination of cadmium in fertilizer samples using high-resolution continuum source graphite furnace atomic absorption spectrometry and slurry sampling[J]. Spectrochimica Acta Part B, 2011, 66(7): 529-535. [7] BAYSAL A, AKMAN S. A practical method for the determination of sulphur in coal samples by high-resolution continuum source flame atomic absorption spectrometry[J]. Talanta, 2011, 85(5): 2662-2665.

[8] OZBEK N, AKMAN S. Method development for the determination of fluorine in toothpaste via molecular absorption of aluminum mono fluoride using a high-resolution continuum source nitrous oxide/acetylene flame atomic absorption spectrophotometer[J]. Talanta, 2012, 94(30): 246-250.

[9] BRANDAO G C, de JESUS R M, da SILVA E G P, et al. Use of slurry sampling for the direct determination of zinc in yogurt by high resolution-continuum source flame atomic absorption spectrometry[J]. Talanta, 2010, 81(4): 1357-1359.

[10] Resano M, Briceño J, Belarra M A. Direct determination of $\mathrm{Hg}$ in polymers by solid sampling-graphite furnace atomic absorption spectrometry: a comparison of the performance of line source and continuum source instrumentation[J]. Spectrochimica Acta Part B: Atomic Spectroscopy, 2009, 64(6): 520-529.

[11] Li Y, Chen S L, Wang S L, et al. Study on Determination Methods of Cadmium Content in Alcoholic Drink [J]. Journal of Xuzhou Institute of Technology(Natural Sciences Edition), 2012, 4(27): 16-19. 